University of Arkansas, Fayetteville

ScholarWorks@UARK

Education Reform Faculty and Graduate

Students Publications

Education Reform

$2-14-2020$

\title{
The Value of Study Abroad Experience in the Labor Market: Findings from a Resume Audit Experiment
}

\author{
Albert Cheng \\ University of Arkansas, Fayetteville \\ Laura Florick \\ University of Arkansas, Fayetteville
}

Follow this and additional works at: https://scholarworks.uark.edu/edrepub

Part of the Educational Assessment, Evaluation, and Research Commons, Educational Leadership Commons, and the Other Educational Administration and Supervision Commons

\section{Citation}

Cheng, A., \& Florick, L. (2020). The Value of Study Abroad Experience in the Labor Market: Findings from a Resume Audit Experiment. Education Reform Faculty and Graduate Students Publications. Retrieved from https://scholarworks.uark.edu/edrepub/89

This Article is brought to you for free and open access by the Education Reform at ScholarWorks@UARK. It has been accepted for inclusion in Education Reform Faculty and Graduate Students Publications by an authorized administrator of ScholarWorks@UARK. For more information, please contact scholar@uark.edu. 


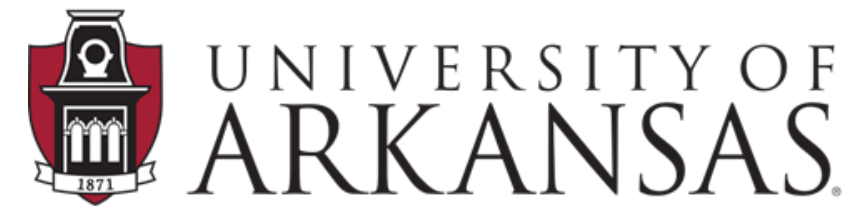

College of Education \& Health Professions Education Reform

\author{
WORKING PAPER SERIES
}

\title{
The Value of Study Abroad Experience in the Labor Market: \\ Findings from a Resume Audit Experiment
}

\author{
Albert Cheng \\ University of Arkansas \\ Laura K. Florick \\ University of Arkansas
}

Last Revised February 7, 2020

EDRE Working Paper 2020-02

The University of Arkansas, Department of Education Reform (EDRE) working paper series is intended to widely disseminate and make easily accessible the results of EDRE faculty and students' latest findings. The Working Papers in this series have not undergone peer review or been edited by the University of Arkansas. The working papers are widely available, to encourage discussion and input from the research community before publication in a formal, peer reviewed journal. Unless otherwise indicated, working papers can be cited without permission of the author so long as the source is clearly referred to as an EDRE working paper. 


\begin{abstract}
Conventional wisdom and some empirical research suggests that study abroad programs enhance skills and personal growth in ways that translate into success in the labor market. However, this research is limited by its inability to address sources of selection bias that may confound the positive relationship between study abroad experience and labor-market success. We conduct a field experiment to overcome these limitations. Using a resume audit, we estimate the causal relationship between participation in study abroad experience and the likelihood of receiving a callback from a potential employer. We also tested for potential heterogeneities by the location (i.e., Asia versus Europe) and length (i.e., two weeks versus one year) of the study abroad experience. Compared to resumes that list no study abroad experience, resumes that list study abroad experience in Asia regardless of length are about 20 percent more likely to receive a callback for an interview if the resume studied. The differences in rates increases to 25 percent when comparing resumes without study abroad experience to those that list two-week programs in Asia. Resumes that list study abroad experience in Europe for one year are 20 percent less likely to receive any callback and 35 percent less likely to receiving a call back for an interview, relative to resumes that do not list study abroad experience. Implications about the value of study abroad are discussed.
\end{abstract}

Keywords: Study abroad, Employment, Resume Audit 


\section{Acknowledgements}

We are grateful to Avi Greene and Caleb Duke for their valuable research assistance on this project. We are also grateful to Julie Trivitt, Josh McGee, and Jay Greene for their comments on earlier drafts of this paper. 
The Value of Study Abroad Experience in the Labor Market:

Findings from a Resume Audit Experiment

According to the Institute of International Education (2019), nearly 350,000

postsecondary students studied abroad during the 2017-18 academic year, a number that has tripled over the past two decades. Currently, about 16 percent of students enrolled in a baccalaureate degree program participated in study abroad at some point during their postsecondary education. Study abroad continues to be promoted by postsecondary institutions because it presumably enhances intercultural competence, self-confidence, civic dispositions, and other skills or knowledge that translate into higher educational attainment and greater success in the labor market. Prior research has indeed documented these differences between students with and without study abroad experience (Dwyer, 2004a, Engle \& Engle, 2004; Heinzmann et al., 2013; Murphy et al., 2014; Norris \& Gillespie, 2008; Orahood, Kruze, \& Pearson, 2004; Orahood, Woolf, \& Kruze, 2008; O’Rear, Sutton, \& Rubin, 2012; Paige et al., 2004; Paige et al., 2009; Rexeisen et al., 2008; Van Hoof \& Verbeeten, 2005). However, these studies are limited by research designs that do not sufficiently account for selection bias, casting doubt on claims that study abroad experiences directly cause these changes in students Thus, it is unclear whether differences between students with and without study abroad experience are attributable to the study abroad experience itself or another unobserved difference between them. In this study, we address this research design limitation and present causal evidence of the effects of study abroad experience on labor market success. To the best of our knowledge, this study represents one of the first efforts to estimate causal effects of study abroad experiences. We conduct an experiment to estimate whether having study abroad experience listed on a resume affects the likelihood of receiving a call back from a prospective employer to 
continue in the job application process. This study follows an extensive body of resume audit studies that examine how employers respond to the gender, race, postsecondary credentials, and other characteristics of job seekers (Bertrand \& Mullainathan, 2004; Deming et al., 2016; Lahey \& Beasley, 2009). We generate fictitious resumes, randomly assigning some of them to include study abroad experience, and compare the callback rates of resumes with and without study abroad experience.

We tested for effect heterogeneity by varying the location and duration of the study abroad experience. It is possible that not all study abroad experiences are equally valued. Are there greater benefits to studying abroad in particular locations? What role does duration play? To address these questions, we randomly assigned some resumes to report study abroad experience in Asian countries and other resumes to report experience in European countries. Furthermore, some study abroad experiences were listed as lasting one year in length, while others were listed as shorter two-week trips.

We find that callback rates are not different between job candidates with and without study abroad experience. However, this aggregate result masks variation in callback rates for job candidates with study abroad experience of different durations and destinations. Compared to resumes that list no study abroad experience, resumes that list study abroad experience in Asia regardless of length are about 20 percent more likely to receive a callback for an interview if the resume studied. The differences in rates increases to 25 percent when comparing resumes without study abroad experience to those that list two-week programs in Asia. Resumes that list study abroad experience in Europe for one year are 20 percent less likely to receive any callback and 35 percent less likely to receiving a call back for an interview, relative to resumes that do not list study abroad experience. 
In the next section, we review the literature on the effects of participating in study abroad programs. We then detail our methods and experimental design to study the effects of study abroad on employability. After that, we present our results and conclude with a discussion our findings.

\section{Background and Prior Research}

\section{Benefits of Study Abroad for the Labor Market}

Graduates of postsecondary institutions who participated in a study abroad program typically look favorably upon their experience. As adults, they indicate that the experience had a large impact on aspects of their lives including their career path, knowledge about the world, and global engagement. Alumni believe that they would neither have accrued these benefits nor have made particular decisions about their career without study abroad experience (Dwyer, 2004a, Norris \& Gillespie, 2008; Orahood, Kruze, \& Pearson, 2004; Orahood, Woolf, \& Kruze, 2008; Paige et al., 2009; Van Hoof \& Verbeeten, 2005). Alumni who participated in a study abroad program believe that these benefits of study abroad translate specifically into labor market success. Surveys find that a large majority of alumni report that the experienced helped them obtain skills to find employment and to be successful at their jobs (Farrugia \& Sanger, 2017; Preston, 2012). Other research documents that individuals with study abroad experience are more likely to graduate on time, receive more job offers, are more likely employed, and find jobs more promptly graduation (Maddux et al., 2014; O'Rear, Sutton, \& Rubin, 2012; Preston, 2012).

Some surveys find that employers do indeed value resumes with study abroad experience (Brandenburg, 2014; Molony, Sower, \& Potts, 2011). These perceptions, however, are not universal. These surveys typically use samples of employers worldwide and, though not emphasized, do demonstrate differences across countries. In particular, employers in the United 
States, value study abroad experiences relatively less than many other European and Asian countries.

Surveys limited to U.S. employers indicate neutral to negative views about job candidates' study abroad experience. Multiple surveys of employers conducted by the Collegiate Employment Research Institute found that almost two-thirds of employers place little importance on study abroad experience and instead place a great deal of importance on prior work experience and internships. The authors mention that some employers characterize study abroad programs as fun but lacking substance (Gardner, Gross, \& Steglitz, 2008).

In another survey administered to U.S. employers, Trooboff et al. (2008) similarly find that they place relatively little importance on study abroad experience. They instead prioritize job candidates who majored in a degree relevant to their firms. However, the authors additionally report that employers place greater emphasis on study abroad experience as the share of their firm's revenue that came from international sources increased. Employers are also more likely to recognize the importance of study abroad as the duration of the program increased or if the employers themselves had studied abroad.

Some surveys find that employers believe that study abroad experiences inculcate students with valuable job skills (Thompson, n.d.). However, this position is not shared by all employers. A significant proportion of employers do not immediately recognize how the skills gained from study abroad experiences are applicable to the workplace (Center for International Mobility \& Demos Helsinki, 2014; Gardner, Gross, \& Steglitz, 2008; Trooboff et al., 2008). Prior research suggests that study abroad programs enhance skills such as intercultural understanding, foreign language fluency, interpersonal skills, tolerance, self-confidence, independence, adaptability, and openness to learning. (Anderson et al., 2006; Bachner \& 
Zeutschel, 2009; Cheiffo, 2007; Dwyer, 2004a; Farrugia \& Sanger, 2017; Heinzmann et al., 2015; Murphy et al., 2014; Paige, Cohen, \& Shively; 2004; Rexeisen et al., 2008; Stone \& Petrick, 2013; Sutton \& Rubin, 2004). Students who participated in programs of longer-durations tend to exhibit higher levels of these characteristics (Engle \& Engle, 2004; Dwyer, 2004b; Ingraham \& Peterson, 2004). Nonetheless, job candidates who merely indicate that they have study abroad experience on a resume or during a job interview without further elaboration may not clearly signal how their experience would translate to being a successful employee (Carley et al., 2011).

\section{Limitations of Prior Literature and Research Gap}

All the research on study abroad, however, is limited by concerns of internal validity. That is, empirical doubt about causal relationships between studying abroad and student outcomes is warranted because of the correlational nature of the work. Some research demonstrates that even prior to any study abroad experience, students who eventually choose to study abroad are systematically different than those who do not on key characteristics including ethnocentrism and interest in foreign language (Fitzsimmons, Flanagan, \& Wang, 2013; Goldstein \& Kim, 2006; Hackney, Boggs, \& Borozan, 2012). In studies that do not control for baseline measures of these outcome variables, researchers are unable to rule out the possibility that differences between students who study abroad and those who do not are simply attributable to these baseline differences (Murphy et al., 2014). In fact, many studies do not even have a control group of students who do not study abroad; it is impossible to estimate the potential effect of a study abroad experience without such a comparison group (Dwyer, 2004a; 2004b, Norris \& Gillespe, 2008). 
Some recent studies have used a pre-post design, collecting outcomes measures both at baseline and after the study abroad trip. Of these studies, some include a control group of students who do not study abroad, while others do not (Anderson et al., 2006; O'rear et al., 2012; Rexeisen et al., 2008). Despite the addition of controlling for baseline measures of the outcome variables of interest as well as other demographic control variables that potentially explain selection into study abroad programs, these studies are still correlational in nature. There may yet be unobserved variables associated with both selection into study abroad programs and growth in the outcome of interest. In this case, the relationship between participation in study abroad and those outcomes is merely spurious; this type of selection bias undermines the internal validity of these studies.

Another limitation of prior research, especially regarding surveys of employers intended to examine whether they value study abroad experiences in job candidates, is the self-reported nature the measures. Besides showing mixed findings of positive, neutral, and negative perceptions of study abroad experiences among employers, these studies rely on what employers say they believe about study abroad (Brandenburg, 2014; Center for International Mobility \& Demos Helsinki, 2014; Gardner, Gross, \& Steglitz, 2008; Molony, Sower, \& Potts, 2011). Employers may believe that study abroad programs foster desirable job skills such as the ability to communicate across cultures and independence (Thompson, n.d.). However, what employers say about what they desire in a candidate and the value of study abroad may not align with actual behavior when it comes to actually hiring someone.

In this study, we address both concerns of prior research and investigate whether employers value study abroad experience through a resume audit. We submit pairs of fictitious resumes to job postings, randomly assigning one of the two resumes to mention study abroad 
experience. We then compare the callback rates from employers for resumes with and without mentions of study abroad. By randomly assigning resumes to mention study abroad as well as randomizing or holding constant other parts of the resume within pairs, we are able to estimate the causal effect of listing study abroad experience in a resume on receiving a callback for a job posting. Moreover, our reliance on employer callbacks as an outcome variable provides us with a behavioral measure of how employers value and respond to study abroad experiences. We elaborate on the details of our methods and experimental design in the next section.

\section{Methods}

\section{Setting for Resume Audit}

We submitted resumes to a job postings listed on a large, popular online job board from September to December of 2019. We sent applications to job postings listed within a 50 mile radius of 17 postsecondary institutions in the Midwestern and Southern U.S. such as the University of Arkansas, University of Kansas, University of Missouri, Oklahoma State, and The University of Texas at Austin. A full list of institutions are listed in Appendix A.

We searched for job postings for entry-level positions suitable for individuals who completed their undergraduate degree in the spring or summer of 2019. All job postings required a postsecondary credential and sought candidates who possessed business-related degrees, namely, jobs that preferred candidates with degrees in business administration, marketing, supply chain management, or information systems. Examples of job titles in these postings included sales and marketing specialist, office administrator, account manager, executive assistant, and outreach coordinator. Job descriptions in these postings listed tasks such as clerical work to manage a firm's portfolio of customers, accounting, project management, customer service or care, making sales, providing administrative assistance, and maintaining websites and other 
media. Roughly half of the job postings listed figures for salaries, the median of which was about $\$ 40,000$.

Our focus on business was motivated by the increasing salience of study abroad to business schools. The rise of international business throughout the past decade has pushed business schools to expand study abroad opportunities and encouraged business students to partake in these opportunities (Gordon, Patterson, \& Cherry, 2014). In the 2017-18 school year, business majors account for one of the largest shares of students studying abroad; 21 percent of all students studying abroad are business students. (Open Doors, 2019). Presumably, study abroad programs provide business students with valuable experience and skills related to interacting with customers from diverse cultures and problem-solving.

\section{Resume Construction and Experimental Design}

In our resume audit, we submitted pairs of fictitious resumes to job openings. The following sections describe how we constructed each component of the resume and set up our experiment.

Study Abroad Experience. To estimate the causal effect of participating in a study abroad program, we constructed resumes that listed study abroad experience and a corresponding resume that did not list study abroad experience. We randomly determined which of the two resumes would indicate study abroad experience and submitted each pair of resumes to the same job posting. In resumes that contained participation in a study abroad program, we listed the experience near the top of the resume along with educational background but under the name and contact information of the job candidate. Given that we are testing the effect of listing study abroad experience on resumes, we attempted to make that attribute as salient as possible. Despite research questioning whether employers valued study abroad experience (Center for 
International Mobility \& Demos Helsinki, 2014; Gardner, Gross, \& Steglitz, 2008; Trooboff et al., 2008), we hypothesized that resumes that included study abroad experiences would be more likely to receive a callback from the employer. Our hypothesis is informed by the conventional wisdom about study abroad programs and other empirical research suggesting some benefits provided by study abroad experiences (Farrugia \& Sanger, 2017; Preston, 2012; Thompson, n.d.).

Among resumes that listed study abroad experience, we also randomly selected the country in which the study abroad experience took place and the duration of the experience. Our aim was to examine whether there were heterogeneous effects in study abroad experience; that is, does the nature of the study abroad experience affect the likelihood of receiving a callback from an employer. The countries included in our experiment are Japan, China, Korea, France, Spain, Italy, and Germany. We selected this set of countries to test whether employers preferred study abroad experience in Asian versus European countries. Our hypothesis was that given the growth of Asian economies and rise international business in Asia, employers would be more likely to call back job candidates with study abroad experience in those countries for such an experience might signal familiarity, connections, and proficiency in skills necessary for (Gordon, Patterson, \& Cherry, 2014; Open Doors, 2019).

After each country was selected, we also randomly selected a duration for the program. To test the value of longer versus shorter programs, study abroad experiences listed on resumes were either assigned a duration of two weeks or one year. The suggestive research evidence and conventional wisdom that postsecondary students realize greater growth and benefits from longer programs (Engle \& Engle, 2004; Dwyer, 2004b; Ingraham \& Peterson, 2004), we hypothesized that resumes with one-year study abroad experiences would be more likely to receive callbacks. 
In sum, we sent out 902 resumes (451 pairs) and within each pair of resumes, one resume listed some kind of study abroad experience, which varied by location and duration while the other resume did not. Table 1 disaggregates the number of resumes we submitted by location and duration of the study abroad experience. For instance, of the resumes we sent out, 219 pairs had a resume that listed a study abroad experience in Asia, and 210 of the pairs had a resume that listed a two-week study abroad experience. Of these resumes, 95 listed study abroad experiences that occurred both in Asia and for two weeks.

Table 1: Counts of Resume Pairs by Location, Duration, and Demographic Characteristics

\begin{tabular}{lc}
\hline & Observations \\
\hline Total Resumes & 902 \\
By Location & \\
Study Abroad in Asia & 219 \\
Study Abroad in Europe & 232 \\
By Duration & \\
One-Year Study Abroad Experience & 210 \\
Two-Week Study Abroad Experience & 240 \\
By Location and Duration & \\
One-Year in Asia & 124 \\
Two-Weeks in Asia & 94 \\
One-Year in Europe & 116 \\
Two-Weeks in Europe & 116 \\
By Gender & \\
Males & 448 \\
Females & 454 \\
By Ethnicity & \\
Whites & 348 \\
Blacks & 198 \\
Hispanics & 174 \\
Asians & 182 \\
\hline
\end{tabular}

Other Job Seeker Characteristics. Aside from study abroad experience, we populated each resume with five additional components: (a) name, (b) contact information, (c) educational background, (d) work experience, (e) skills, and (f) extracurricular activities and awards. All of 
the content for these components are drawn from actual resumes to enhance the external validity of our findings.

Name. Because prior research suggests that the preference for job candidates varies by demographic characteristics such as race and gender, we randomized race and gender only across job postings, not within job postings (Bertrand \& Mullainathan, 2004). In other words, for a given job posting, we randomly selected a gender (i.e., male or female) and race (i.e., White, Black, Hispanic, or Asian) combination and then randomly generated two names that fit that gender and race combination based on lists of the most popular names of children born around the year 2000. By holding constant gender and race across the two resumes to be sent to each job vacancy, we ensure that any differences in callback rates are not attributable to differences in these demographic characteristics.

Contact Information. We generated a set of email addresses and phone numbers to be used for each resume. We regularly checked these email and voicemail accounts for callbacks by employers. As is typically done in resume audits, we did not respond to any callbacks. For the addresses, we listed units in large apartment complexes.

Educational Background. Every resume listed completion of a bachelor's degree program in the spring of 2019 from one of the 17 institutions in our study setting describe above (see also Appendix A). We did not create any resumes that listed post-baccalaureate credentials; nor did we create resumes where the fictitious individual did not complete a postsecondary education. Our aim was to create the archetypal recent graduate in business who was applying for an entrylevel job near their alma mater. Specific degrees included those in business administration, marketing, supply chain management, accounting, or information systems as long as the 
postsecondary institution offered such a degree. The name of the degree was randomly selected once the institution was selected.

Work Experience. In order to create fictitious resumes that mimicked real resumes and strengthen the generalizability of our study, we used the same job board to which we were submitting resumes to sample nearly 700 resumes of real individuals who completed a business program in the spring of 2019 from the institutions in our study setting. We collected up to the three most recent work experiences listed in each of these resumes. After populating the postsecondary institution and degree in each of our fictitious resumes, we randomly selected a work history from the resume of a real individual who attended the same postsecondary institution and degree. The random selection of work history helps to ensure that in the aggregate, callbacks are not driven by differences in work histories across pairs.

Skills. We similarly populated our fictitious resumes with skills that were listed on the real resumes that we sampled. To avoid potential confounding effects, we randomly selected lists of skills from the sampled resumes and added them to the fictitious resumes as they were.

Extracurricular Activities and Awards. Most real resumes also listed participation in a variety of extracurricular activities. These comprise membership in student groups, leadership in student groups, volunteering work, and awards. As with skills and work experience, we randomly selected these items and populated our fictitious resumes with this content.

\section{Analytic Strategy}

We use a regression framework to compare callback rates between resumes that list study abroad experience with those that do not. Our unit of analysis is the resume. The dependent variable is a binary indicator of whether the particular resume received a callback from a prospective employer. We consider any personal phone message or email left by the prospective 
employer desiring additional information about the job candidate or a request for a job interview a callback. We also run estimate models in which we compare rates of callbacks that specifically requested an interview. Our independent variable of interest is binary indicator of whether the resume included study abroad experience. Our regression models additionally include indicators for resume pairs given that we sent pairs of resumes to the same job posting. Strictly speaking, we do not need any additional control variables to estimate the effect of having study abroad experience because we held race, gender, educational background, and degree program constant within pairs and randomized all the content in each resume.

To investigate whether the effect of listing study abroad varies by location or duration of the study abroad experience, we estimated the same model as describe above but also included three additional variables: (a) a binary variable indicating that the experience occurred in Asia, (b) a binary variable indicating that the experience lasted one year, and (c) a term that interacts the indicator variables for Asian location and one-year duration. The regression coefficients of this model will estimate differences between all four types of trips.

\section{Results}

\section{General Results}

We first present the results comparing callback rates between resumes with and without study abroad experience. As is evident in Figure 1, there are no differences in callback rates between these two types of resumes, whether we consider any callbacks or callbacks that specifically request interviews. About 29 percent of resumes that do not list study abroad experience received a callback from an employer, which is the same as the rate for resumes that list any study abroad experience. On the other hand, 19 percent of resumes, whether or not they listed some type of study abroad experience, received a callback from an employer specifically 
asking for an interview. The full set of regression coefficient estimates for these results and all subsequent results are listed in Appendix B.

Figure 1: Callback Rates for Resumes with and without any Study Abroad Experience

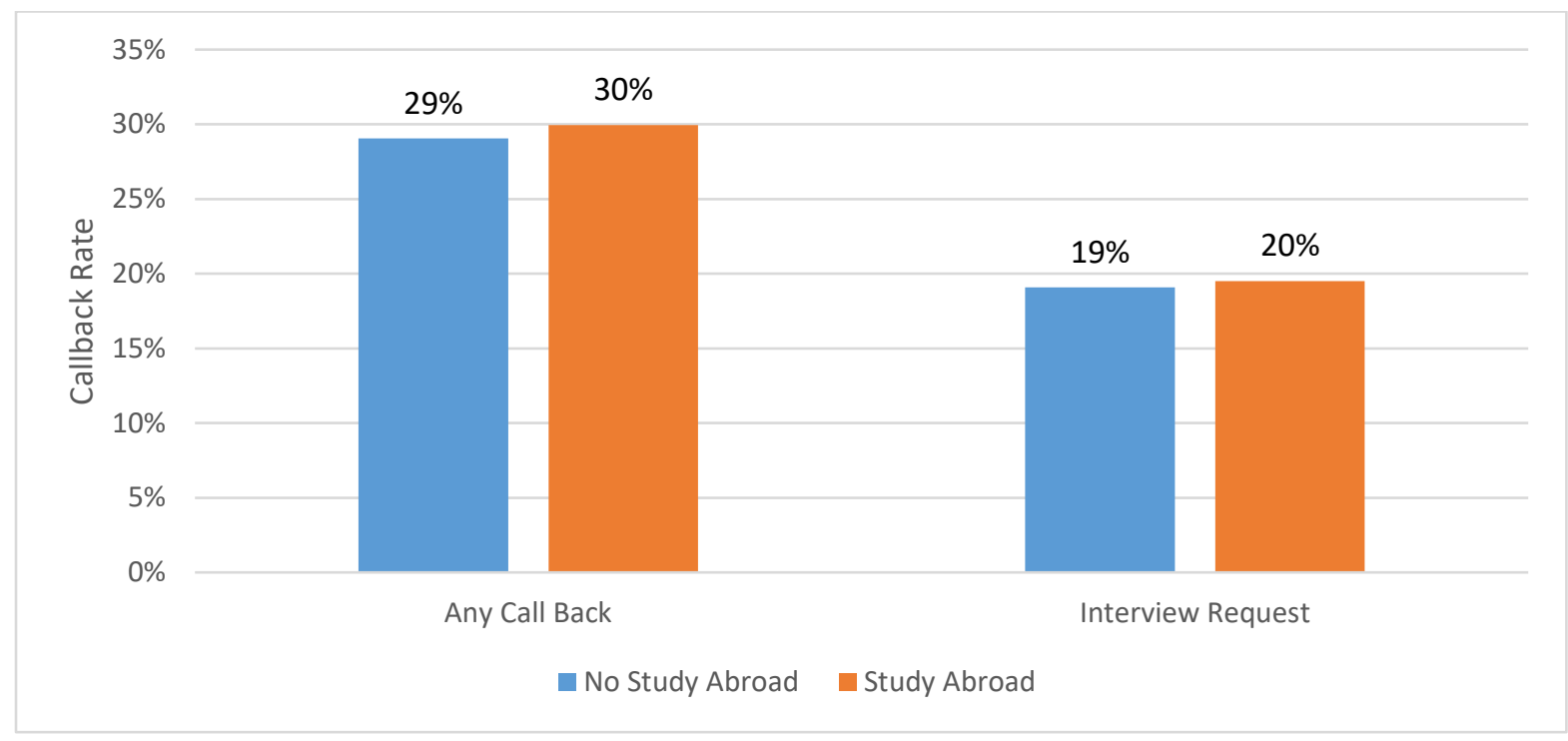

\section{Results by Location}

These results, however, mask heterogeneity by location and duration. When we compare callback rates by location, we find some evidence of benefits to studying abroad in Asia. As shown in Figure 2, about 33 percent of resumes that list study abroad experience in Asia receive any type of callback. This rate is about 4 percentage points higher than the rate for resumes without study abroad experience but falls short of conventional levels of statistical significance $(\mathrm{p}=0.14)$. The callback rate for resumes that list study abroad experience in Europe is noticeably lower at 27 percent but also statistically insignificant.

In contrast, 23 percent of resumes that list study abroad experience in Asia receive a callback that specifically requests an interview. This rate is 4 percentage points higher than the rate for resumes that do not list study abroad experience. In percent difference terms, this is about a 21 percent increase and statistically significant at the 0.1 level. Again, the callback rate 
for resumes that list study abroad experience in Europe are lower than the rate for resumes without study abroad experience, though the difference is not statistically significant.

Figure 2: Results by Study Abroad Location

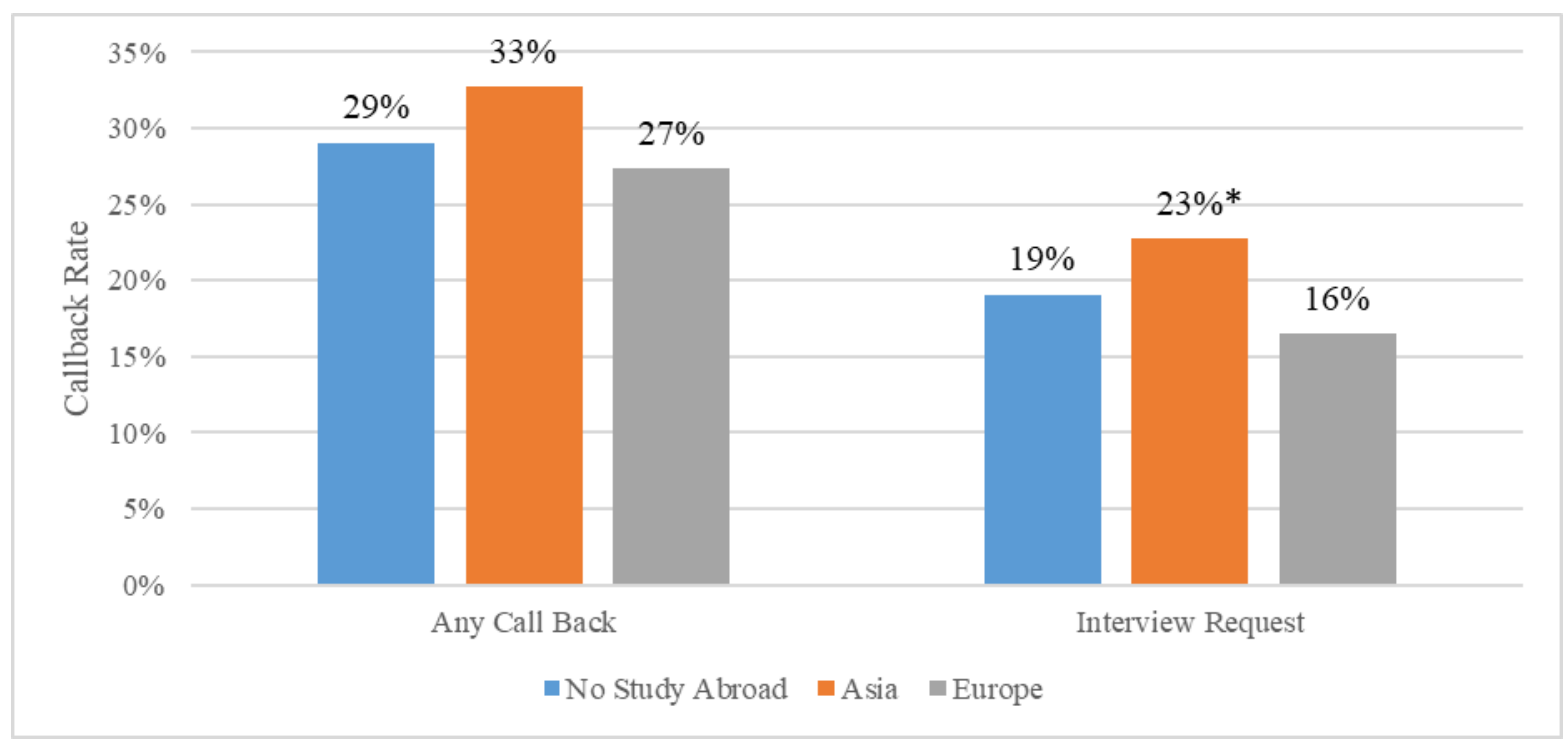

Note: *Statistically different from the No Study Abroad group at the 0.1 level.

\section{Results by Duration}

When we compare callback rates by the duration of study abroad programs, we do not find evidence of effect heterogeneity for resumes that either list one-year or two-week experiences. These results are shown in Figure 3. In absolute terms, callback rates are two percentage points lower for resumes that list one-year programs compared to resumes that list no study abroad experience, but the result is not statistically significant nor substantively large. Conversely, callback rates are two percentage points higher for resumes that list two-week point. Again, however, this result is neither statistically nor substantively significant. We find similar patterns when we restrict our outcome of interest to callbacks that include an interview request. Figure 3: Results by Study Abroad Duration 


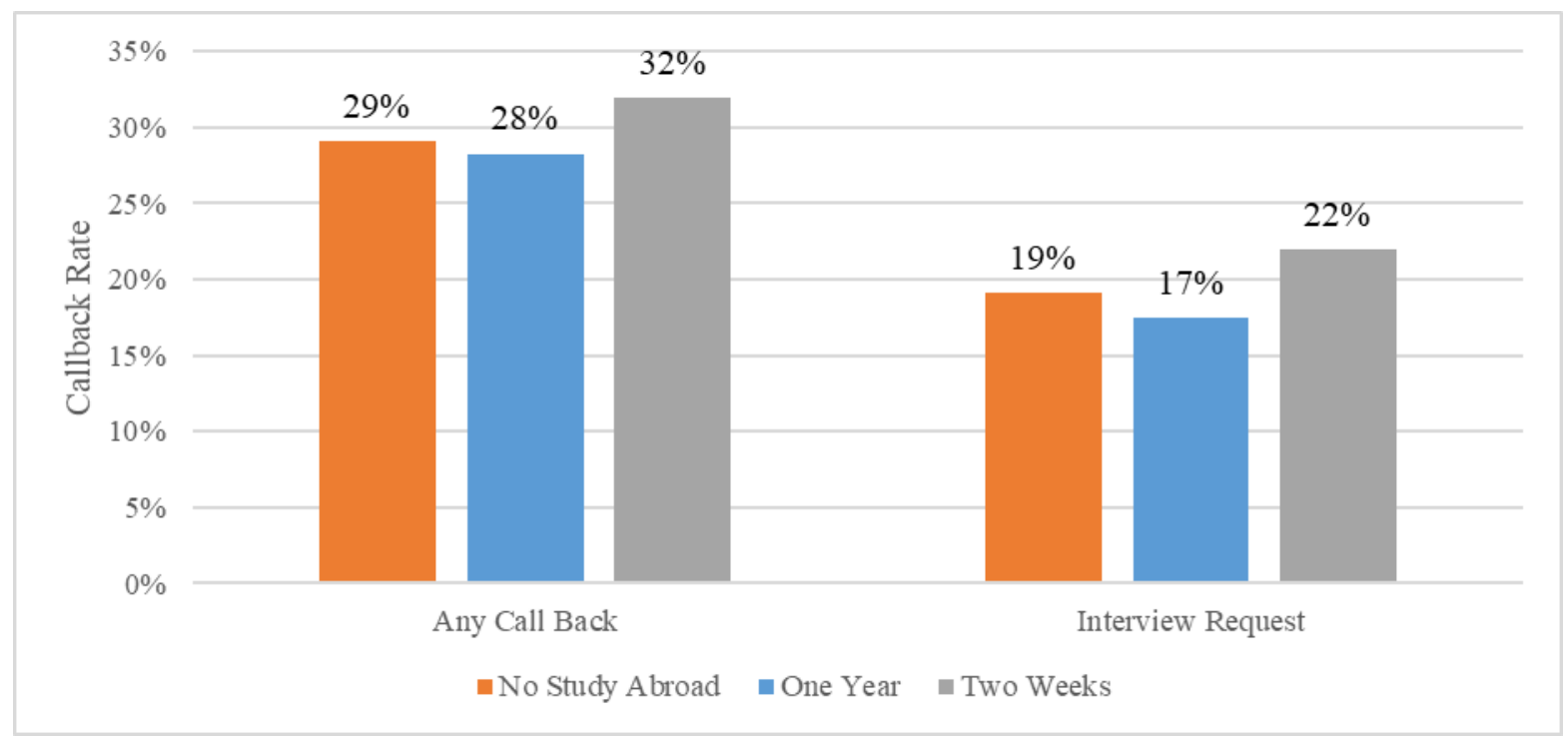

\section{Results by Location and Duration}

Finally, we examined the interaction of location and duration of study abroad experience and their effects on employer callbacks. Figure 4 displays results for any type of callback from an employer, while Figure 5 displays results for interview requests.

Figure 4. Callback Rates by Location and Duration

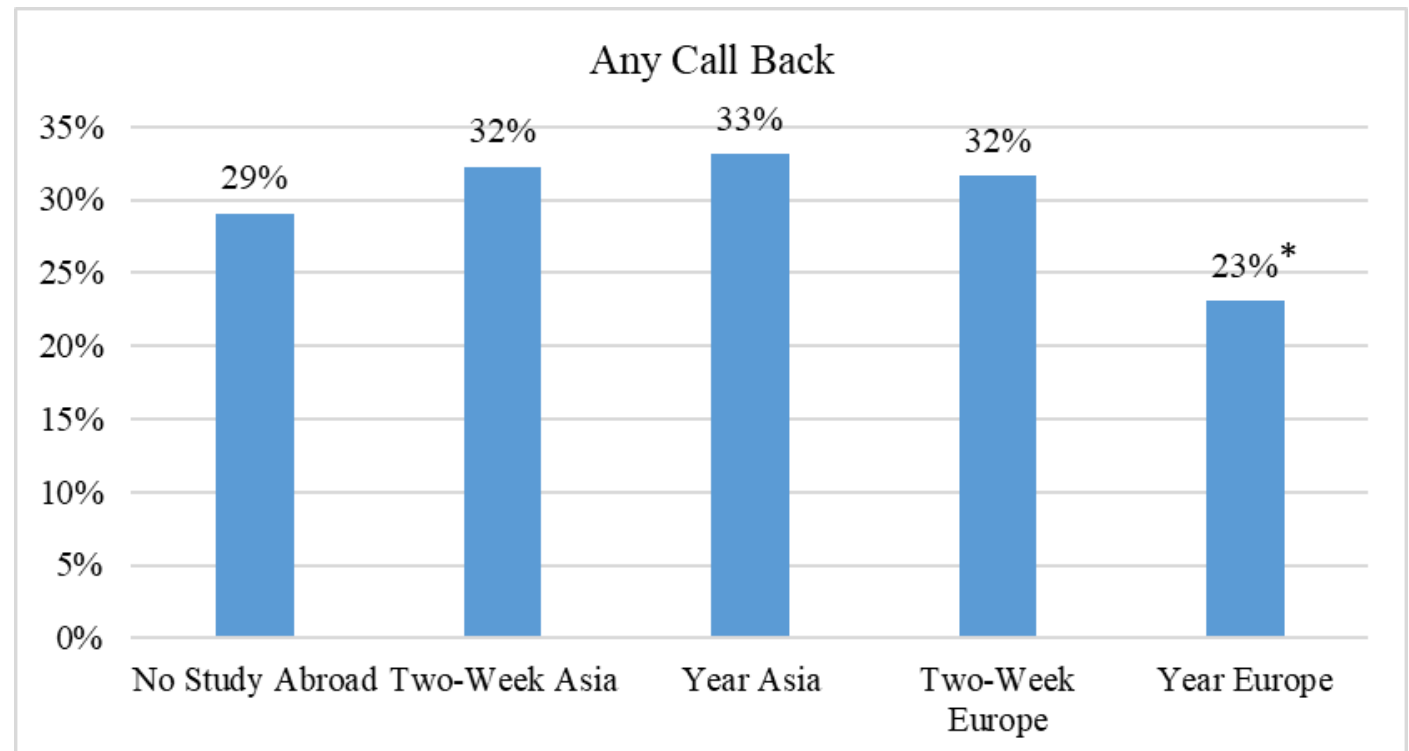

Note: *Statistically different from the No Study Abroad group at the 0.1 level. 
Figure 5: Interview Request Rates by Location and Duration

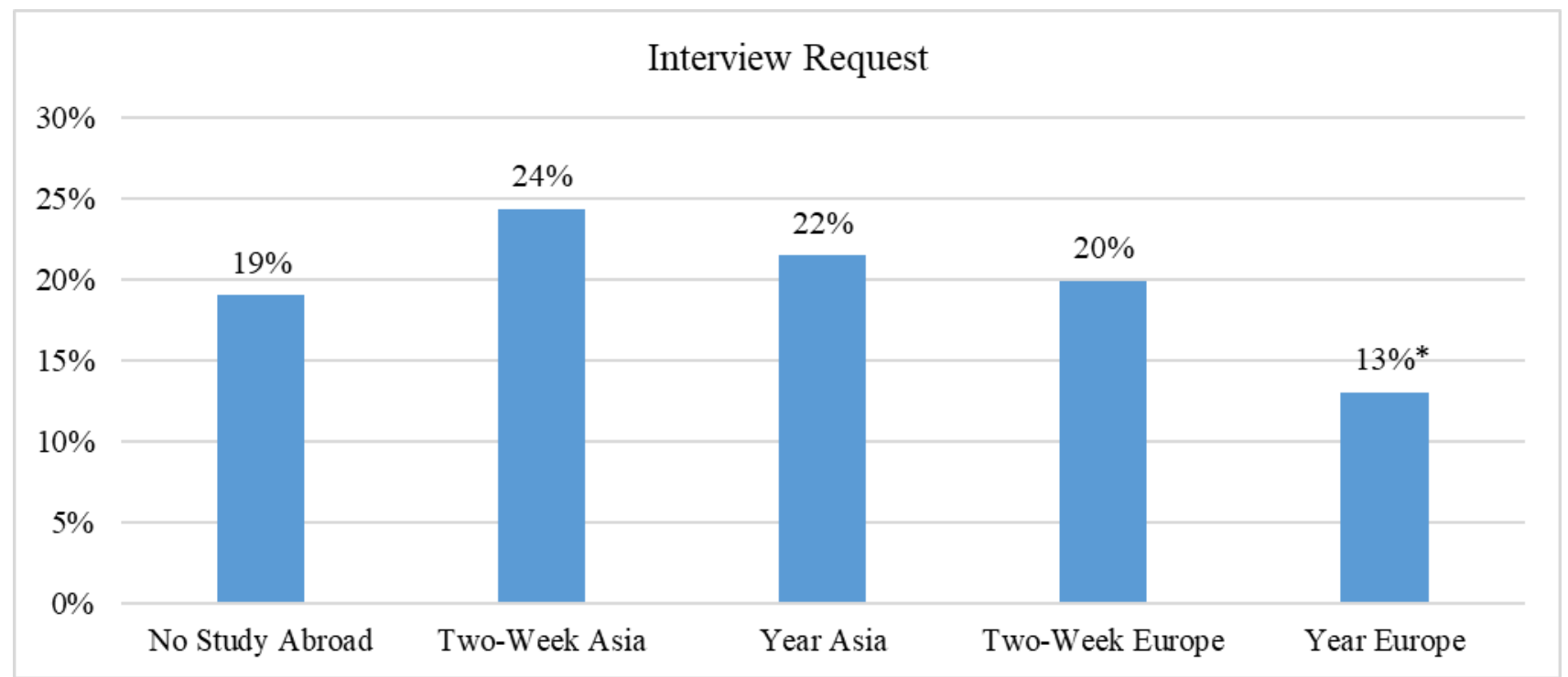

Note: *Statistically different from the No Study Abroad group at the 0.1 level.

In both figures, there is a clear negative effect of listing a year-long study abroad experience in Europe. About 23 and 13 percent of resumes that list such an experience receive any callback and interview requests, respectively. These rates are six percentage points lower than corresponding rates for resumes that list no study abroad experience. For any callback, the six percentage-point drop represents a decrease of 20 percent; for interview requests, it represents a decrease of about 32 percent. In contrast, the callback rates for resumes that list twoweek study abroad experiences in Europe are very similar to callback rates for resumes that list no study abroad experience.

Results in Figures 4 and 5 also demonstrate that the greatest effect on increasing callback rates seems to come from listing participation in two-week study abroad programs to Asia. About 33 percent of all resumes that list any duration of study abroad experience in Asia receive callbacks. This rate, though not statistically significant, is 4 percentage points higher than the 29 percent of resumes without study abroad experience that receive callbacks and represents a 14 percent increase in the likelihood of receiving a callback. Turning to callbacks that specifically 
include interview requests, we find that 24 percent of resumes that list two-week study abroad experiences in Asia receive such requests. This rate is 5 percentage points higher than the rate for resumes that do not list study abroad experiences, representing a 25 percent increase. Although substantively large, this effect falls just short of conventional levels of statistical significance $(\mathrm{p}=0.11)$.

\section{Discussion and Conclusion}

We use a resume audit to examine the effects of study abroad experience on labor market outcomes. We find that there is some value to listing study abroad experience on resumes, but the nature of that experience matters. That is, different types of study abroad programs do not signal the same value to employers as measured by callback rates. There appears to be benefits to listing study abroad experience on resumes if job candidates participated in programs in Asia, especially if they are shorter in duration. Benefits from participating in programs in Europe are less pronounced and, in fact, can be hurtful in the case of year-long experiences.

These patterns are consistent with the hypotheses that we developed at the outset of the study. Given the rise of international business in Asia (Gordon, Patterson, \& Cherry, 2014 Open Doors, 2019), we predicted that there would be stronger benefits to having study abroad experience in Asia, especially since we generated fictitious resumes of recent college graduates who majored in a business-related field. Our hypotheses about the effects of duration were less certain. Although one year abroad might signal the acquisition of valuable skills that employers desire, it may come with substantial opportunity costs. For example, studying abroad for one year may mean that the job candidate has one fewer year of an internship or work experience that may also be valued by employers. Indeed, we find suggestive evidence that job candidates who spend a year in Europe may incur some of these costs. 
All that said, we acknowledge some limitations to this study. First, success in the labor market extends well beyond receiving an invitation for a job interview. Other indicators, such as whether one is offered a job after the interview, earnings, longevity in a job, and job productivity, are at least as important for evaluating the effects of study abroad experience on labor market success. Our study cannot address these outcomes.

Moreover, our study focuses on a particular point of the job search process — the callback. There are many other key points in the job search process, and it remains plausible that study abroad experience may be beneficial at those points. Other research, for example, suggests that study abroad experience plays a formative role in enabling students to discerning their career path prior to applying for any jobs (Norris \& Gillespie, 2008; Orahood, Kruze, \& Pearson, 2004; Orahood, Woolf, \& Kruze, 2008). After the resume submission stage, job seekers who participated in study abroad may benefit from being able to recount their experience at length during an interview. That time is an opportunity explicitly connect skill gains from study abroad experiences to how those skills might promote success on the job may lie with the job candidate (Carley et al., 2011; Gardner, Gross, \& Steglitz, 2008; Tillman, 2011). We encourage further empirical research of the role of study abroad at other stages of the job search process.

Our work is consistent with surveys of employers who say they do not prioritize study abroad experience when considering job candidates. It is important to emphasize that our work also suggests that employers actually do what they say; they not only claim to not prioritize study abroad experiences but do not callback job seekers with such experiences at higher rates (Center for International Mobility \& Demos Helsinki, 2014; Gardner, Gross, \& Steglitz, 2008). Nor does our research speak to the actual skills that participants of study abroad programs may have acquired from their experience. Even if we have identified these skills, however, there is still a 
lack of research ascertaining if skill gains from study abroad translate directly into gains in worker productivity or other indicators of labor market success. So even while study abroad experiences may benefit job candidates by helping them obtain a job, it is not clear whether the experience enhances job performance. An empirical test of this question would be beneficial.

We additionally note that we created fictitious resumes of undergraduate students who earned degrees in marketing, supply chain management, accounting, and information systems from institutions in the Midwestern and Southern United States. We also focused on applying to entry-level jobs suitable for candidates with this type of educational background. It is not certain that our results generalize to other degree fields, job markets, and job positions. We encourage further study to address the limitations of considering the archetypal just-graduated business school that we considered in our study. Furthermore, one could question whether the value of study abroad varies with the business cycle. Our resume audit was conducted during a time of low unemployment. Does the value of study abroad experience change during an economic recession when hiring slows and jobs are scarcer? External validity concerns aside, this study is one of the first to examine the causal effects of study abroad. More work of this nature to test the conclusions of a large body of non-causal research documenting differences between students who participate in study abroad programs and others who do not would enable scholars and higher education practitioners to understand the true value of study abroad programs. 


\section{References}

Anderson, P, L. Lawton, R.J. Rexeisen and A. Hubbard, (2006). Short-term study abroad and intercultural sensitivity: A Pilot Study. International Journal of Intercultural Relations, 30(4), 457-469.

Brandenburg, U. (2014). The Erasmus impact study: Effects of mobility on the skills and employability of students and the internationalisation of higher education institutions. Brussels: European Commission.

Center for International Mobility, \& Demos Helsinki. (2014). Hidden competencies: Vast amounts of skills and competencies developed through international experiences go unrecognized. Helsinki: Finnish Ministry of Education and Culture.

Bertrand, M., Mullainathan, S. (2004). Are Emily and Greg more employable than Lakisha and Jamal? A field experiment on labor market discrimination. American Economic Review 94(4), 991-1013.

Carley, S., Stuart, R., \& Dailey, M. P. (2011). Short-term study abroad: An exploratory view of business student outcomes." Journal of Management Policy and Practice 12(2), 44-53.

Deming, D.J., Yuchtman, N., Abulafi, A., Goldin, C., \& Katz, L.F. (2016). The value of postsecondary credentials in the labor market: An experimental study. American Economic Review, 106(3), 778-806.

Dwyer, M. (2004a). Charting the impact of studying abroad. International Educator, 13(1), 1420.

Dwyer, M. (2004b) More is better: The impact of study abroad program duration. Frontiers: The Interdisciplinary Journal of Study Abroad, 10, 151-163. 
Engle, L. \& Engle, J. (2004). Assessing language acquisition and intercultural sensitivity Development in relation to study abroad program design. Frontiers: The Interdisciplinary Journal of Study Abroad, 10, 219-236.

Farrugia, C., \& Sanger, J. (2017). Gaining an employment edge: The impact of study abroad on 21 st century skills and career prospects in the United States. Washington, DC: Institute of International Education, Inc.

Fitzsimmons, S.R., Flanagan, D.J., \& Wang, X.A. (2013). Business students' choice of shortterm or long-term study abroad opportunities. Journal of Teaching in International Business, 24(2), 125-137.

Goldstein, S. B., \& Kim, R. I. (2006). Predictors of US college students' participation in study abroad programs: A longitudinal study. International Journal of Intercultural Relations, $30(4), 507-521$.

Gordon, P.J., Patterson, T., \& Cherry, J. (2014). Increasing international study abroad rates for business students. Academy of Educational Leadership Journal, 18(3), 77-86.

Hackney, K., Boggs, B., \& Borozan, A. (2012). An empirical study of student willingness to study abroad. Journal of Teaching in International Business, 23(2), 123-144.

Heinzmann, S., Künzle, R., Schallhart, N., Müller, M. (2015). The effect of study abroad on intercultural competence: Results from a longitudinal quasi-experimental study. Frontiers: The Interdisciplinary Journal of Study Abroad, 26, 187-208.

Institute of International Education. (2019). Open doors 2019: Report on international educational exchange. Washington, DC: Institute of International Education, Inc. Lahey, J.N., \& Beasley, R.A. (2009). Computerizing audit studies. Journal of Economic Behavior and Organization, 70(3), 508-514. 
Maddux, W.M., Bivolaru, E. , Hafenbrack, A.C., Tadmor, C.T., Galinsky, A.D. (2014).

Expanding opportunities by opening your mind: Multicultural engagement predicts job market success through longitudinal increases in integrative complexity. Social Psychological and Personality Science, 5(5), 608-615.

Molony, J., Sower, B., \& Potts, D. (2011). QS global employer survey report 2011: How employers value an international study experience. London: QS.

Murphy, D., Sahakyan, N., Yong-Yi, D., Magnan, S.S. (2014). The impact of study abroad on the global engagement of university graduates. Frontiers: The Interdisciplinary Journal of Study Abroad, 24, 1-24.

Open Doors. (2019). 2019 fast facts. Washington, DC: Institute of International Education, Inc.

Orahood, T., Kruze, L, \& Pearson, D.E. (2004). The impact of study abroad on business students' career goals. Frontiers: The Interdisciplinary Journal of Study Abroad, 10, 117130.

Orahood, T., Woolf, J., \& Kruze, L. (2008). Study abroad and career paths of business students. Frontiers: the Interdisciplinary Journal of Study Abroad, 17, 133-141.

O’Rear, I., Sutton, R. L., \& Rubin, D. L. (2012). The effect of study abroad on college completion in a state university system. Athens, GA: University of Georgia.

Paige, R. M. (2004). Instrumentation in intercultural training. In D. Landis, J. M. Bennett, \& M. J. Bennett (Eds.), Handbook of intercultural training (3rd ed.), pp. 85-128. Thousand Oaks, CA: Sage

Rexeisen, R.J., Andreson, P.H., Lawton, L., \& Hubbard, A.C. (2008). Study abroad and intercultural development: A longitudinal study. Frontiers: The Interdisciplinary Journal of Study Abroad, 17, 1-20. 
Stone \& Petrick, (2013). The educational benefits of travel experiences: A literature review. Journal of Travel Research, 52(6), 731-744.

Thompson, J.W. (n.d.). An exploration of the demand for study overseas from American students and employers. Washington, DC: Institute of International Education, Inc.

Tillman, M. (2011). AIFS guide to student and career development. Stamford, CT. American Institute for Foreign Study.

Trooboff, S., Vande Berg, M., \& Rayman, J. (2008). Employer attitudes towards study abroad. Frontiers: The Interdisciplinary Journal of Study Abroad, 15, 17-33.

Van Hoof, H., \& Verbeeten, M. (2005). Wine is for drinking, water is for washing: Student opinions about international exchange programs. Journal of Studies in International Education, 9(1), 42-61.

Xu, M., de Silva, C.R., Neufeldt, E., Dane, J.H. (2013). The impact of study abroad on academic success: An analysis of first-time students entering Old Dominion University, Virginia, 2000-2004. Frontiers: the Interdisciplinary Journal of Study Abroad, 23, 90-103. 


\section{Appendix A:}

\section{Institutions Included in the Study}

Appendix Table A1: Institutions and Locations

\begin{tabular}{|l|l|}
\hline Name & Location \\
\hline University of Arkansas & Fayetteville, AR \\
\hline University of Illinois at Chicago & Chicago, IL \\
\hline University of Illinois at Urbana-Champaign & Champaign, IL \\
\hline University of Kansas & Lawrence, KS \\
\hline Kansas State University & Manhattan, KS \\
\hline University of Missouri & Columbia, MO \\
\hline Missouri State University & Springfield, MO \\
\hline University of Missouri, Kansas City & Kansas City, MO \\
\hline University of Missouri, St Louis & St. Louis, MO \\
\hline University of Nebraska & Lincoln, NE \\
\hline University of Nebraska at Omaha & Omaha, NE \\
\hline University of Oklahoma & Norman, OK \\
\hline Oklahoma State University & Stillwater, OK \\
\hline University of Texas at Austin & Austin, TX \\
\hline University of Texas at Dallas & Dallas, TX \\
\hline University of Texas at San Antonio & College Station, TX \\
\hline Texas A\&M & \\
\hline
\end{tabular}




\section{Appendix B:}

\section{Regression Results}

Table B1: Regression Results

\section{(1)}

\section{Panel A \\ Dependent Variable: Any Callback}

Study Abroad

Asia

Year

Asia*Year

0.009

$(0.017)$

$-0.017$

(0.024)

0.054

(0.034)

0.028

0.009

0.026

$(0.025)$

(0.030)

(0.034)

0.006

$(0.050)$

$-0.037$

(0.034)

$-0.086 *$

(0.048)

0.095

(0.069)

Mean for Resumes without Study Abroad

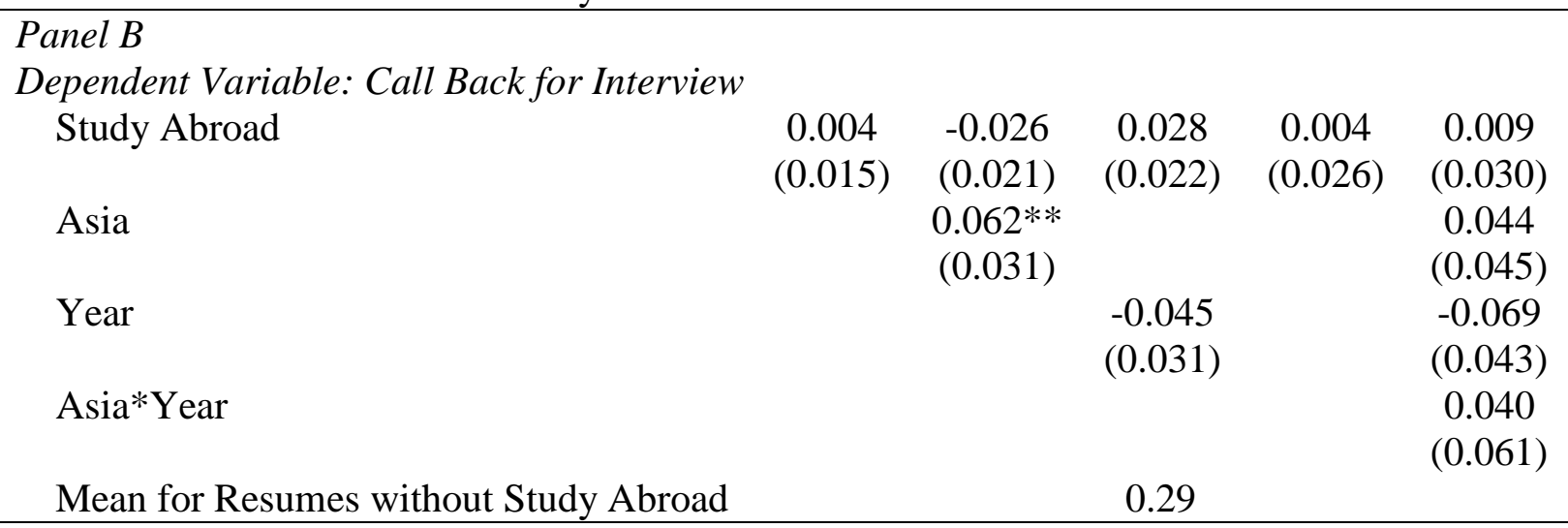

Notes. All models include fixed effects indicating the pair of resumes that were sent to a specific job opening. $\mathrm{N}=902$. ${ }^{*} \mathrm{p}<0.1 ; * * \mathrm{p}<0.05$. 